\title{
ANALISIS EFEKTIVITAS DAMPAK PENINGKATAN JUMLAH BESARAN PENGHASILAN TIDAK KENA PAJAK TERHADAP PENERIMAAN PAJAK PENGHASILAN ORANG PRIBADI PADA KPP PRATAMA MANADO
}

\author{
Stefi Cristiani Weol ${ }^{1}$, Grace B. Nangoi ${ }^{2}$, Anneke Wangkar ${ }^{3}$ \\ ${ }^{1,2,3}$ Jurusan Akuntansi, Fakultas Ekonomi dan Bisnis, Universitas Sam Ratulangi, Jl. Kampus Bahu, Manado, \\ 95115, Indonesia \\ E-mail : Steffiweol@gmail.com
}

\begin{abstract}
Non-Taxable Income is the minimum living cost to be able to live a decent life. Changes Last Non Taxable Income namely No.101/PMK.010/2016,began to apply on January 1,2016 until present. The purpose of this study is to analyze the effect of their changes Non-Taxable Income on income tax revenue. The analytical method used is descriptive data. The results showed that PTKP changes have a good impact on the growth of the number of taxpayers in each year, but considered not effective against income tax revenue. This shows that the increase of PTKP is not the dominant factor in influencing income tax revenue.
\end{abstract}

Keywords :Non-Taxable Income, Tax Income (PPh) Article 21

\section{1PENDAHULUAN}

Pajak merupakan sumber yang sangat penting dalam memenuhi dan menunjang kebutuhan negara. Pemanfaatan pendapatan suatu negara mencerminkan bagaimana negara tersebut untuk maju. Indonesia menggunakan salah satu penerimaan pendapatan negara yang berpotensi besar yaitu pajak yang menyumbang rata-rata lebih dari $70 \%$ dari keseluruhan pendapatan negara dalam berbagai fungsi kenegaraan (Salim, 2013).

Penerapan besarnya perubahan PTKP telah disesuaikan dengan perkembangan didalam dunia ekonomi yang semakin lama mengalami peningkatan yang sangat pesat. Perubahan PTKP banyak menimbulkan dampak bagi wajib pajak orang pribadi. Terkait dengan pernyataan Presiden, maka Menteri Keuangan memutuskan untuk menetapkan Peraturan Menteri Keuangan Republik Indonesia Nomor 101/PMK.010/2016 tentang Penyesuaian Besaran Penghasilan Tidak Kena Pajak yang berlaku efektif per 1 Januari 2016 untuk menggantikan Peraturan Menteri Keuangan Nomor 122/PMK.0101/2015.

Sebagaimana diketahui bahwa PTKP adalah unsur pengurang dalam penghitungan pajak penghasilan orang pribadi, maka dengan adanya kenaikan PTKP ini diharapkan untuk menciptakan multiplier effect di bidang perpajakan. Dan dengan meningkatnya PTKP, maka diharapkan pula kepatuhan Wajib Pajak akan semakin meningkat dalam melaporkan Surat Pemberitahuan(SPT) dan membayar pajaknya dengan tepat waktu sehingga dengan ini dapat meningkatkan penerimaan negara dari sektor pajak khususnya. Tujuan penelitian ini adalah untuk menganalisis dampak perubahan PTKP terhadap pertumbuhan jumlah wajib pajak orang pribadi dan penerimaan pajak penghasilan orang pribadi serta kendala dan upaya yang dilakukan oleh KPP Pratama Manado.

\section{TINJAUAN PUSTAKA}

\subsection{Pengertian Pajak}

Pengertian Pajak menurut Undang-Undang No. 28 Tahun 2007 pasal 1 ayat 1 pajak adalah kontribusi wajib kepada negara yang terutang oleh orang pribadi atau badan yang bersifat memaksa berdasarkan Undang-Undang, dengan tidak mendapatkan imbalan secara langsung dan digunakan untuk keperluan negara bagi sebesar-besarnya kemakmuran rakyat. 


\subsection{Konsep Pajak Penghasilan}

Undang-Undang Republik Indonesia Nomor 7 Tahun 1987 tentang Pajak Penghasilan sebagaimana telah diubah terakhir dengan Undang-Undang Nomor 36 Tahun 2008 menjelaskan bahwa undang-undang ini mengatur tentang pengenaan Pajak Penghasilan terhadap subjek pajak berkenaan dengan penghasilan yang diterima atau diperolehnya dalam tahun pajak, bahwa subjek pajak tersebut dikenai pajak apabila menerima atau memperoleh penghasilan.

\subsection{Fungsi Pajak}

Pajak mempunyai beberapa fungsi yaitu:

1 Fungsi Anggaran (Budgetair), yaitu dimana pajak sebagai sumber dana bagi pemerintah untuk membiayai pengeluaran-pengeluarannya.

2. Fungsi mengatur (Regulerend), yaitu dimana pajak sebagai alat untuk mengatur dan melaksanakan kebijakan pemerintah baik dalam bidang sosial maupun ekonomi.

\subsection{Subjek Pajak Penghasilan}

Pajak Penghasilan (PPh) termasuk dalam pajak subjektif, artinya pajak dikenakan karena ada subjeknya yakni yang telah memenuhi kriteria yang telah ditetapkan dalam peraturan perpajakan. Sehingga terdapat ketegasan bahwa apabila tidak ada subjeknya, maka jelas tidak dapat dikenakan $\mathrm{PPh}$. Subjek pajak yang menerima atau memperoleh penghasilan disebut Wajib Pajak. Dalam Undang-Undang Nomor 36 Tahun 2008, yang menjadi subjek pajak adalah:

a. - Orang Pribadi; yaitu wajib pajak yang memiliki penghasilan baik yang berasal dari dalam negeri maupun luar negeri, yang dapat dipakai untuk konsumsi atau untuk menambah kekayaan wajib pajak yang bersangkutan, dengan nama dan dalam bentuk apapun.

b. Badan

- Warisan yang belum terbagi;

\section{c. Bentuk Usaha Tetap}

\subsection{Penghasilan Tidak Kena Pajak (PTKP)}

Penghasilan Tidak Kena Pajak adalah pengurang dari penghasilan bersih wajib pajak yang dapat menstabilkan kebutuhan hidup wajib pajak, agar kehidupan wajib pajak dapat terpenuhi dengan baik. Bagi wajib pajak orang pribadi (WPOP), untuk mendapatkan Penghasilan Tidak Kena Pajak (PTKP) harus dikurangi terlebih dahulu dari penghasilan neto suatu PTKP. Besaran PTKP dapat disesuaikan dengan keadaan keluarga menurut UndangUndang ketentuan Pasal 6 ayat 3 tentang Pajak Penghasilan. Besaran PTKP diatur dalam Peraturan Menteri Keuangan Republik Indonesia Nomor 101/PMK.010/ 2016 yang diperoleh adalah sebagai berikut :

1. Rp.54.000.000,- untuk wajib pajak orang pribadi itu sendiri;

2. Rp. 4.500.000,- tambahan untuk wajib pajak yang telah menikah;

3. Rp.54.000.000,-tambahan untuk seorang istri yang penghasilannya digabung dengan penghasilan suami;

4. Rp. 4.500.000,-tambahan untuk setiap anggota keluarga sedarah (ayah, ibu, dan anak kandung) dan semenda (mertua dan anak tiri), dalam garis keturunan lurus, serta anak angkat yang menjadi tanggungan sepenuhnya, paling banyak tiga orang untuk setiap keluarga.

\subsection{Manfaat PTKP bagi Wajib Pajak}

Penghasilan Tidak Kena Pajak memiliki manfaat bagi Wajib Pajak khususnya untuk wajib pajak orang pribadi, akan manfaat ini tidak dapat dimiliki oleh wajib pajak badan seperti CV, yayasan, lembaga, dan badan lain sesuai dengan Pasal 7 Undang-Undang Pajak Penghasilan. Direktorat Jenderal Pajak dalam proses menghimpun pajak, menerapkan 
beberapa aturan dalam menentukan pajak yang harus dibayarkan oleh Wajib Pajak, beberapa diantaranya adalah biaya jabatan, Penghasilan Tidak Kena Pajak (PTKP) dan tarif pajak berlapis yang dikenakan terhadap penghasilan kena pajak Wajib Pajak Orang Pribadi. Fasilitas-fasilitas tersebut diberikan kepada Wajib Pajak Orang Pribadi (WPOP) agar tercipta keadilan pada setiap Wajib Pajak dari WP kaya berpenghasilan tinggi sampai kepada WP yang berpenghasilan menengah kebawah, selain itu fasilitas tersebut diberikan agara masyrakat tidak terlalu terbebani dengan beban pajak yang harus dibayarnya (Andiyanto, 2013). Manfaat yang dapat diperoleh wajib pajak orang pribadi antara lain :

1. Mengurang Pajak yang harus dibayar oleh Wajib Pajak Orang Pribadi (WPOP);

2. Memberikan lebih banyak penghasilan yang dapat dibawa pulang kepada Wajib Pajak Orang Pribadi (WPOP);

3. Mengurangi biaya hidup, dikarenakan setiap ada tanggungan berupa kawin atau menikah, memiliki anak dan tanggungan karena hubungan keluarga bertambah maka PTKP akan bertambah dengan maksimal 3 tanggungan seperti sedarah lurus satu derajat (Ayah, Ibu, Anak Kandung), sedarah ke samping satu derajat (Saudara Kandung), semenda lurus satu derajat (Mertua, Anak Tiri) dan semenda ke samping satu derajat (Saudara Ipar).

\subsection{Penelitian Terdahulu}

1. Hoirina Rosindah Sabela (2014) melakukan penelitian berjudul: Pengaruh Kenaikan Penghasilan Tidak Kena Pajak terhadap Tingkat Kepatuhan Wajib Pajak Orang Pribadi pada Kantor Wilayah Direktorat Jenderal Pajak-Jawa Barat. Hasil menunjukkan bahwa kenaikan PTKP bukan faktor dominan untuk mempengaruhi tingkat kepatuhan wajib pajak.

2. Ari Akbar Irawan (2016) melakukan penelitian berjudul: Pengaruh Perubahan Penghasilan Tidak Kena Pajak dan Tarif Pajak Penghasilan Orang Pribadi terhadap Penerimaan Pajak Penghasilan pada Kantor Wilayah Direktorat Jenderal Pajak Jawa Barat. Hasil menunjukkan bahwa perubahan PTKP dan tarif pajak berpengaruh terhadap penerimaan pajak penghasilan. Persamaan penelitian ini adalah sama-sama menggunakan perhitungan PTKP.

3. Amina Lainutu (2013) melakukan penelitian berjudul: Pengaruh Jumlah Wajib Pajak PPh 21 terhadap Penerimaan PPh 21 pada KPP Pratama Manado. Hasil menunjukkan bahwa jumlah wajib pajak mempunyai keeratan hubungan yang cukup kuat dan searah terhadap penerimaan $\mathrm{PPh}$ Pasal 21. Persamaan penelitian ini adalah sama-sama menggunakan perhitungan PTKP.

4. Putri Indrayanti (2014) melakukan penelitian berjudul: Analisis Pengaruh Kenaikan Penghasilan Tidak Kena Pajak terhadap Penerimaan Pajak Penghasilan pada Kantor Pelayanan Pajak Pratama Sukabumi, Bandung Tegallega, dan Bandung Karees Tahun 2012-2013. Hasil menunjukkan bahwa kenaikan PTKP tidak memiliki pengaruh terhadap penerimaan pajak penghasilan pasal 21 pada ketiga Kantor Pelayanan Pajak. Persamaan penelitian ini adalah sama-sama menggunakan perhitungan PTKP.

\section{METODE PENELITIAN}

\subsection{Jenis Penelitian}

Jenis penelitian yang digunakan adalah penelitian kualitatif atau berbentuk uraian berupa penjelasan secara tertulis dari sumber-sumber yang terkait dalam penelitian. Gambaran yang akurat diperoleh dari mengumpulkan, mengklarifikasi data sehingga akan memberikan hasil yang konkrit pada permasalahan dan kemudian dianalisis sehingga dapat ditarik suatu kesimpulan (Sedarmayanti \& Syarifudin, 2011:25).

\subsection{Tempat dan Waktu Penelitian}

Peneliti melakukan penelitian pada Kantor Pelayana Pajak Pratama Manado yang beralamat di Jl.Gunung Klabat, Tj.Batu, Wanea, Kota Manado, Sulawesi Utara, Indonesia, 
Kode Pos 95117. Waktu penelitian ini dilakukan pada bulan Februari 2018.

\subsection{Prosedur Penelitian}

1. Melakukan pengkajian awal dengan melakukan studi literatur baik studi kepustakaan maupun membaca melalui internet.

2. Melakukan pengidentifikasian masalah, merumuskan, menetapkan tujuan, dan manfaat penelitian.

3. Perancangan dan persiapan survei pada objek penelitian yang telah ditentukan.

4. Pengumpulan data baik primer maupun sekunder.

5. Melakukan pengolahan data, membahasnya kemudian menarik kesimpulan dan memberikan saran-saran guna melengkapi penelitian.

\subsection{Sumber Data}

Sumber data yang penulis gunakan dalam penelitian ini adalah:

1. Data Primer

Data yang diperoleh dalam melakukan penelitian ini merupakan sumber-sumber asli yang berasal dari Kantor Pelayan Pajak Pratama Manado yang merupakan hasil dari wawancara guna mendapatkan jawaban atas permasalahan yang akan diteliti mengenai jumlah penerimaan pajak penghasilan orang pribadi ( $\mathrm{PPh} 21$ ) dan jumlah wajib pajak orang pribadi.

2. Data Sekunder

Data yang diperoleh secara tidak langsung, dimana pengambilan data ini dimaksudkan untuk mendapatkan data-data yang mendukung penelitian ini, yang diperoleh dari dokumen-dokumen yang berkaitan dengan pembahasan, seperti buku atau referensi lainnya seperti studi kepustakaan.

\subsection{Teknik Pengumpulan Data}

1. Penelitian Lapangan/Wawancara

Peneliti mengadakan pengamatan secara langsung ke tempat objek yang akan diteliti dimana data yang diambil diperoleh dengan menggunakan metode wawancara dengan pihak-pihak yang terkait dengan penyediaan informasi atau data yang diperlukan dalam penelitian.

2. Penelitian Kepustakaan

Penelitian ini dilakukan dengan cara mencari kerangka referensi dan landasan teori. Penelitian ini diperoleh baik dari buku-buku, Undang-Undang dan peraturan serta karya ilmiah yang relevan dengan ide penelitian baik dalam bentuk skripsi, makalah termasuk dari sumber media yaitu internet yang kemnudian menjadi literatur pengumpulan data.

\subsection{Metode Analisis}

Berdasarkan masalah dan teknik pengumpulan data penulis menggunakan teknik deskriptif kualitatif yaitu dengan cara menggambarkan kenyataan dan keadaan atas suatu objek dalam bentuk uraian kalimat berdasarkan keterangan dari pihak-pihak yang berhubungan langsung dengan penelitian ini. Efektivitas data penelitian ini yaitu dapat dilakukan dengan langkah sebagai berikut :

1. Efektivitas Presentase Penerimaan Pajak pada KPP Pratama Manado yaitu dengan membandingkan antara realisasi penerimaan pajak dibagi dengan rencana penerimaan pajak kemudian dikalikan dengan 100\% dengan rumusan sebagai berikut :

$$
\text { Efektivitas }=\frac{\text { Realisasi Penerimaan Pajak }}{\text { Rencana Penerimaan Pajak }} \times 100 \%
$$


Dari hasil rumusan presentase tersebut yaitu :

Tabel 3.1

Interprestasi Nilai Efektivitas

\begin{tabular}{|c|c|}
\hline Presentase & Kriteria \\
\hline$>101 \%$ & Sangat Baik \\
\hline $91-100 \%$ & Efektif \\
\hline $81-90 \%$ & Cukup \\
\hline $61-80 \%$ & Kurang Efektif \\
\hline$<60 \%$ & Tidak Efektif \\
\hline
\end{tabular}

Sumber : Depdagri, Kemendagri No.690.900.327 (Rima Adelina, 2012)

2. Untuk menghitung tingkat pertumbuhan dapat dihitung dengan rumus :

Keterangan :

$$
\text { Tingkat Pertumbuhan Jumlah WP }=\frac{\mathrm{WP}_{\mathrm{n}}-\mathrm{WP}_{\mathrm{n}-1}}{\mathrm{WP}_{\mathrm{n}-1}} \times 100 \%
$$

$\mathrm{WP}_{\mathrm{n}} \quad$ : Jumlah Wajib Pajak pada tahun sekarang

$\mathrm{WP}_{\mathrm{n}-1}$ : Jumlah Wajib Pajak pada tahun sebelumnya

Sumber : Dina Nadia \& Sunandar ( 2016 )

\section{HASIL ANALISIS DAN PEMBAHASAN}

\subsection{Hasil Penelitian}

4.1.1. Perkembangan Jumlah Wajib Pajak Orang Pribadi pada KPP Pratama Manado

Untuk mengetahui perkembangan jumlah wajib pajak orang pribadi di KPP Pratama Manado dapat dilihat dari tabel 4.1 dalam empat tahun terakhir yaitu tahun 2012-2016 yang telah diperoleh peneliti dalam penelitian lapangan di Kantor Pelayanan Pajak Manado yang disajikan dalam tabel berikut ini :

Tabel 4.1

Jumlah Wajib Pajak Orang Pribadi Tahun 2012-2016 Pada KPP Pratama Manado

\begin{tabular}{|c|c|c|}
\hline NO & Tahun & Jumlah \\
\hline 1. & 2012 & 93.316 \\
\hline 2. & 2013 & 101.891 \\
\hline 3. & 2014 & 110.492 \\
\hline 4. & 2015 & 119.612 \\
\hline 5. & 2016 & 130.462 \\
\hline
\end{tabular}

Sumber : Bagian PDI KPP Pratama Manado

\subsubsection{Target dan realisasi penerimaan pajak penghasilan orang pribadi tahun 2012- 2016 \\ Untuk mengetahui perkembangan jumlah penerimaan pajak penghasilan orang pribadi} di KPP Pratama Manado dapat dilihat dari tabel 4.2 dalam empat tahun terakhir yaitu tahun 2012-2016 yang telah diperoleh peneliti dalam penelitian lapangan di Kantor Pelayanan Pajak Manado yang disajikan dalam tabel berikut ini : 


\section{Tabel 4.2}

Target dan Realisasi Penerimaan Pajak Penghasilan Orang Pribadi Tahun 2012-2016

\begin{tabular}{|c|c|c|c|}
\hline No. & Tahun & Target & Realisasi \\
\hline 1. & 2012 & Rp. 26.783.745.324 & Rp. 20.891.690.154 \\
\hline 2. & 2013 & Rp. 42.365 .123 .200 & Rp. 23.659.658.778 \\
\hline 3. & 2014 & Rp. 21.796.948.000 & Rp. 17.526.061.480 \\
\hline 4. & 2015 & Rp. 20.059.717.000 & Rp. 10.247.794.895 \\
\hline 5. & 2016 & Rp. 34.873.135.000 & Rp. 18.377.222.184 \\
\hline
\end{tabular}

Sumber : Bagian PDI KPP Pratama Manado

\subsection{Pembahasan}

4.2.1. Presentase Pertumbuhan Jumlah Wajib Pajak Orang Pribadi Tahun 2012-2016 Presentase perubahan PTKP terhadap jumlah wajib pajak orang pribadi di KPP Pratama Manado di evaluasi dengan menggunakan rumus :

$$
\text { Tingkat Pertumbuhan Jumlah WP }=\frac{\mathrm{WP}_{\mathrm{n}}-\mathrm{WP}_{\mathrm{n}-1}}{\mathrm{WP}_{\mathrm{n}-1}} \times 100 \%
$$

Keterangan :

$\mathrm{WP}_{\mathrm{n}}:$ Jumlah Wajib Pajak pada tahun sekarang

$\mathrm{WP}_{\mathrm{n}-1}$ : Jumlah Wajib Pajak pada tahun sebelumnya

Tabel 4.3

Presentase Jumlah Wajib Pajak Orang Pribadi Tahun 2012-2016 Pada KPP Pratama Manado

\begin{tabular}{|c|c|c|c|}
\hline No & Tahun & Jumlah & Presentase \\
\hline 1 & 2012 & 93.316 & - \\
\hline 2 & 2013 & 101.891 & $9,19 \%$ \\
\hline 3 & 2014 & 110.492 & $8,44 \%$ \\
\hline 4 & 2015 & 119.612 & $8,25 \%$ \\
\hline 5 & 2016 & 130.462 & $9,07 \%$ \\
\hline
\end{tabular}

Sumber : Bagian PDI KPP Pratama Manado (hasil olahan)

Berdasarkan Tabel 4.3 diatas, terkait tingkat pertumbuhan jumlah wajib pajak orang pribadi pada KPP Pratama Manado memiliki tingkat pertumbuhan yang selalu meningkat setiap tahunnya. Presentase pertumbuhan rata-rata wajib pajak orang pribadi adalah sebesar $8,74 \%$ setiap tahunnya. Pertumbuhan jumlah wajib pajak orang pribadi memicu untuk meningkatkan penerimaan pajak penghasilan pada KPP Pratama Manado.

\subsubsection{Efektivitas Perubahan PTKP Terhadap Penerimaan Pajak Penghasilan Orang Pribadi}

Efektivitas penerimaan di evaluasi dengan menggunakan rasio efektivitas, dengan rumus sebagai berikut :

$$
\text { Efektivitas }=\frac{\text { Realisasi Penerimaan Pajak }}{\text { Target Penerimaan Pajak }} \times 100 \%
$$

Efektivitas Perubahan PTKP Terhadap Wajib Pajak Orang Pribadi yang dilakukan pada Kantor Pelayanan Pajak Pratama Manado dalam meningkatkan jumlah penerimaan pajak orang pribadi dalam beberapa tahun ini dapat dilihat bahwa hasilnya kurang efektif. Hal ini dapat dilihat dari data dibawah ini yang memperlihatkan jumlah penerimaan pajak penghasilan orang pribadi setelah perubahan PTKP pada tahun 2012-2016. Berdasarkan 
rumus efektivitas diatas dapat diketahui tingkat efektivitas pajak penghasilan orang pribadi di KPP Pratama Manado tahun 2012 2016, untuk lebih jelasnya dapat dilihat pada tabel berikut ini.

Tabel 4.4

Target dan Realisasi Penerimaan Pajak Penghasilan Orang Pribadi Tahun 2012-2016

\begin{tabular}{|c|c|c|c|c|c|}
\hline No. & Tahun & Target & Realisasi & $\%$ & $\begin{array}{c}\text { Kriteria } \\
\text { Efektivitas }\end{array}$ \\
\hline 1. & 2012 & Rp. 26.783.745.324 & Rp. 20.891.690.154 & $78,00 \%$ & Kurang Efektif \\
\hline 2. & 2013 & Rp. 42.365 .123 .200 & Rp. 23.659 .658 .778 & $55,85 \%$ & Tidak Efektif \\
\hline 3. & 2014 & Rp. 21.796 .948 .000 & Rp.17.526.061.480 & $80,41 \%$ & Cukup Efektif \\
\hline 4. & 2015 & Rp. 20.059.717.000 & Rp.10.247.794.895 & $51,09 \%$ & Tidak Efektif \\
\hline 5. & 2016 & Rp. 34.873.135.000 & Rp. 18.377.222.184 & $52,70 \%$ & Tidak Efektif \\
\hline
\end{tabular}

Sumber : Bagian PDI KPP Pratama Manado (Data diolah)

Berdasarkan tabel 4.4 terkait hasil analisis efektivitas tersebut menunjukkan bahwa pertumbuhan jumlah wajib pajak orang pribadi pada KPP Pratama Manado, tidak berpengaruh terhadap penerimaan jumlah pajak penghasilan di KPP Pratama Manado, disebabkan karena jumlah wajib pajak yang wajib SPT tidak seluruhnya menyampaikan SPT dan adanya jumlah wajib pajak efektif menjadi wajib pajak non efektif dikarenakan penghasilan Wajib Pajak Orang Pribadi (WPOP)-nya masih banyak yang dibawah PTKP sehingga tidak dikenakan potongan PPh Pasal 21.

\section{KESIMPULAN DAN SARAN}

\subsection{Kesimpulan}

1. Hasil analisis membuktikan bahwa Kenaikan Penghasilan Tidak Kena Pajak belum memberikan hasil yang efektif terhadap penerimaan pajak penghasilan disebabkan karena masih banyaknya Wajib Pajak Orang Pribadi (WPOP) yang penghasilannya dibawah PTKP sehingga target penerimaan pajak penghasilan di KPP Pratama Manado belum efektif.

2. Kenaikan Penghasilan Tidak Kena Pajak merupakan kebijakan yang ditetapkan Pemerintah dalam mengimbangi perkembangan ekonomi yang terjadi di Indonesia dan di harapkan dapat mendongkrak tingkat kesejahteraan masyarakat. Dalam pengaruhnya terhadap pertumbuhan wajib pajak pada KPP Pratama Manado selama 5 (lima) tahun, yaitu pada tahun 2012-2016 memberikan pengaruh yang efektif terhadap pertumbuhan jumlah wajib pajak yang setiap tahun mengalami pertumbuhan.

\subsection{Saran}

Kebijakan dalam menyesuaikan Penghasilan Tidak Kena Pajak sangat penting adanya demi kesejahteraan masyarakat. Kebijakan ini agar selalu dilakukan peninjauan kembali dengan mempertimbangkan keadaan kondisi ekonomi global dan ekonomi masyarakat. Hasil penelitian menunjukkan bahwa kenaikan Penghasilan Tidak Kena Pajak (PTKP) di KPP Pratama Manado masih rendah pengaruhnya terhadap penerimaan pajak penghasilan.

Namun, peningkatan PTKP dalam jangka pendek akan mengakibatkan penurunan penerimaan pajak oleh negara sehingga perlu dilakukan ekstentifikasi dengan menambah jumlah wajib pajak baru. Penambahan jumlah wajib pajak baru dapat dilakukan dengan memberikan NPWP bagi wajib pajak pekerja ataupun memberikan fasilitas tertentu bagi pekerja yang memiliki NPWP sehingga wajib pajak pekerja yang memiliki penghasilan diluar gaji dapat membayarkan pajaknya. 


\section{DAFTAR PUSTAKA}

Adelina, Rima. 2013. Analisis Efektivitas dan Kontribusi Penerimaan Pajak Bumi dan Bangunan (PBB) terhadap Pendapatan Daerah di Kabupaten Gresik. http://jurnalmahasiswa.unesa.ac.id/index.php/jurnalakuntansi/article/download/752/536

Farnika, Novita Erawati. 2013. Analisis Penerimaan Pajak pada Kantor Wilayah Direktorat Jenderal Pajak Wajib Pajak Besar Setelah Pemberlakuan Kenaikan PTKP. Jurnal Unesa, 1(2), hal 8-12

Irawan, Ari Akbar. 2016. Pengaruh Perubahan Penghasilan Tidak Kena Pajak dan Tarif Pajak Penghasilan Orang Pribadi terhadap Penerimaan Pajak Penghasilan pada Kantor Wilayah Direktorat Jenderal Pajak Jawa Barat. http://elib.unikom.ac.id/files/disk1/709/jbptunikompp-gdl-ariakbarir-35438-10unikom_a-1.pdf

Julianti, Debi. 2015. Pengaruh Kenaikan Pendapatan Tidak Kena Pajak terhadap Penerimaan Pajak Penghasilan Orang Pribadi dan Implikasinya pada Pertumbuhan Ekonomi, Fakultas Ekonomi dan Bisnis, Universitas Komputer Indonesia. http://elib.unikom.ac.id/files/disk1/711/jbptunikompp-gdl-debijliant-35536-5unikom_d-r.pdf

Mardiasmo. Perpajakan Edisi Revisi Terbaru 2016, Andi.Yogyakarta

Peraturan Menteri Keuangan Republik Indonesia Nomor 101/PMK.010/2016 tentang Penyesuaian Besaran Penghasilan Tidak Kena Pajak

Resmi, Siti. 2013. Perpajakan: Teori dan Kasus, Edisi 7, Jakarta: Salemba Empat.

Sabela, Hoirina Rosindah. 2014. Pengaruh Kenaikan Penghasilan Tidak Kena Pajak terhadap Tingkat Kepatuhan Wajib Orang Pribadi pada Kantor Wilayah Direktorat Jenderal Pajak-Jawa Barat I.https://repository.widyatama.ac.id/xmlui/handle/123456789/4515

Sedarmayanti \& Hidayat Syarifudin. 2011. Metodologi Penelitian. Mandar Maju. Bandung Sumarsan, Thomas. 2017. Perpajakan Indonesia, Edisis 5, Jakarta Barat.

Undang-Undang Nomor 36 Tahun 2008 tentang Perubahan Keempat atas Undang-Undang Nomor 7 tahun 1983 tentang Pajak Penghasilan.

Waluyo. 2013. Perpajakan Indonesia, Jakarta:Salemba Empat 